\title{
Design and Study on Management Tools of Land Data Center for Integration of Urban and Rural Areas
}

\author{
Shiwu XU, Xiuzhen LIU \\ China University of Geosciences (Wuhan), China
}

\begin{abstract}
The rapid development of urbanization requires land management business should change the former single systematic pattern, and advance to integration of functions and data sharing. In order to meets the requirement, this paper presents a new thinking for land management pattern, and management tools of data center for integration of urban and rural areas. The tools were based on MapGIS, which have made the management of multi-subjects, multi-areas, multi-sources and multi-measurement data possible. The techniques of this system are designed accord with national related standard. Experimental result shows that the tools have obvious technical advantage in land resource business integration management.
\end{abstract}

Keywords: integration of urban and rural areas territory resource; data center; data sharing

\section{城鄉一體化國土資源資料中心管理工具的設計與研究}

\author{
徐世武, 劉秀珍 \\ 中國地質大學（武漢）資訊工程學院，武漢 430074
}

\begin{abstract}
摘 要: 城市化的飛速發展要求國土資源管理業務擺脫以前的單系統模式, 逐步向資料共用、功能一體 化方向發展。為適應這種發展趨勢, 對當前土地管理系統中存在的管理模式提出新的思路, 研究並設 計出城鄉一體的國土資源資料中心管理工具。基於 MAPGIS 的城鄉一體化資料中心管理工具採用專題 融合的新模式, 把以前二元管理融合為一體, 實現了多專題、多區域、多源、多尺度的一體化資料中 心管理，實踐中能夠實現了國土資源業務管理的一體化，具有明顯的技術優勢。
\end{abstract}

關鍵字：城鄉一體化；資料中心；資料共用

\section{1. 引 言}

國民經濟的蓬勃發展促進了城市化進程的加快, 使“小、散、亂”的農村工業經濟格局向現代化的大工 業園區經濟格局轉變, 實際上, 城鄉分離格局的打破 不僅體現在地理分佈, 更體現於城鄉結合部的飛速發 展、城市與農村經濟的日益融合, 延續多年的“城鄉” 二元體制正在被打破。我國國土資源管理由於二元體 制的影響一直保持著城鄉獨立管理的模式，使得傳統
的國土資源資料中心管理軟體逐漸形成了針對不同專 題進行管理的互相獨立的軟體集結構。地籍管理業務 主要依據《城鎮地籍調查規程》和《土地利用現狀調 查規程》分別對城鎮和農村土地開展地籍調查, 城市 地區專注於土地權屬的管理, 農村地區專注于土地利 用情況的管理，為此形成了許多分別基於城鎮和農村 的軟體來為國土部門服務。近年來隨著經濟的蓬勃發 展, 城市與鄉村的差別在迅速減小, 城市化與地籍管 理中的城鄉獨立管理模式的矛盾日益突出, 分離模式 
的軟體已不能滿足當今國土管理工作的需要, 因此圍 繞土地權屬與利用兩方面的多專題統一管理軟體的研 製工作迫在眉睫。

\section{2. 目前的研究狀況}

\section{1 相關背景}

在長期傳統土地管理模式影響下，形成了農村土 地管理重用途輕權屬, 城鎮土地管理重權屬輕用途的 局面。隨著國家新的土地分類辦法的實施, 地籍管理 將權屬與土地利用融為一體, 建立農村與城鎮地籍管 理系統軟體統一、資料結構統一、組織和管理方式統 一的城鄉一體化管理系統成為國土資源管理系統化發 展的必然趨勢。同時, 近年來市場經濟的發展和土地 使用制度的改革, 也要求對原有城市土地分類進行適 當調整。隨著城鄉一體化進程的加快, 科學實施全國 土地和城鄉地政統一管理已提到議事日程, 實施統一 管理的基本條件亦已基本具備, 普遍要求在原有兩個 土地分類和調查成果的基礎上, 進行城鄉土地統一分 類, 匯總出全國城鄉統一的土地資料成果和其他調查 成果, 以利於全國城鄉土地的統一管理和調查成果的 擴大應用。

我國經濟的飛速發展, 特別是資訊技術的發展, 尤其在高速運算、大容量存儲、高速網路、海量商用 資料庫等技術方面取得了重大突破，也極大的推進了 GIS 技術的發展, 從而為處理城鄉一體後的網路海量 多源空間資料打下了堅實的基礎。

\section{2. 目前面臨的主要問題和研究現狀}

\subsection{1 側重專題按區域的資料管理模式}

城鄉分治的專題資料庫管理系統是以某一區域 單一的專題資料為核心建設的。傳統的地籍管理系
統涉及利用與權屬兩大核心基礎資料, 並據此分別 建立相互獨立的應用系統和資料庫系統（縣市級城 鎮地籍管理系統和土地利用現狀資料庫系統）。這 種地籍區域化管理方式和資訊化建設模式, 給系統 的建設和應用都帶來許多問題。尤其在經濟發展活 躍的城鄉結合部的地籍管理工作中暴露無疑。城鄉 結合部是土地最活躍、變化最頻繁的區域, 是地籍 管理的難點，無論是原針對農村的土地利用管理模 式還是針對城鎮的權屬管理模式, 這種嚴格按城鄉 區域來管理的模式都難以適用城鄉結合部由於征地 開發整理等專案帶來的土地不斷變化的要求, 給管 理工作帶來巨大困難。

\subsection{2 單區域的部分專題結合管理模式}

將一定區域中邏輯上的部分專題資料統一設計 形成物理上的一個專題資料庫，然後基於專題資料開 發相應的資料庫管理系統。如某區域的國土資源資料 庫中包含有多種專題資料, 其中也包含權屬專題資料 與利用專題資料，在資料庫設計時，以土地利用圖斑 為專題的基礎細粒度資料形成中等粒度的權屬宗地專 題資料, 在物理上結合形成單層的地籍專題資料（權 屬十利用），邏輯上又構成相互獨立的兩層，具體設 計實現如下圖 1 。

這種方式實現了權屬與利用專題的統一管理，既 保證了資料的邏輯一致性，又滿足了不同業務專題資 料間必要的相對邏輯獨立性，但是還没有有效的對規 劃、耕地保護、定級估價等業務專題進行管理，不夠 全面, 多專題的跨層分析無法實現; 並且簡單的把這 些管理業務內容都按如此的模式加入到一個系統中, 又會造成介面複雜系統臃腫，系統使用人員都是某一 方面的專家, 只會使用其中的一部分功能, 其他部分 對其則是無用的。

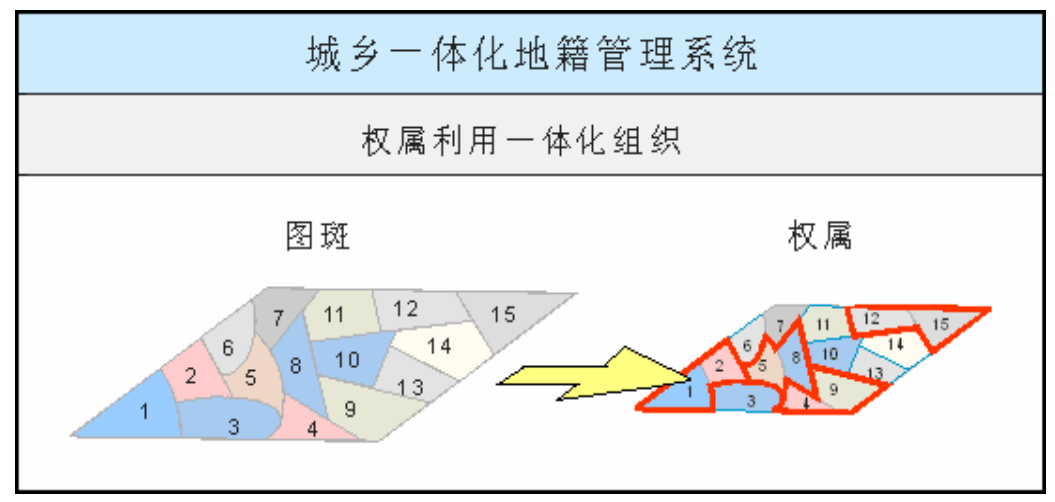

圖 1. 城鄉一體化地籍管理架構圖 
這種方式實現了權屬與利用專題的統一管理, 既 保證了資料的邏輯一致性, 又滿足了不同業務專題資 料間必要的相對邏輯獨立性, 但是還没有有效的對規 劃、耕地保護、定級估價等業務專題進行管理, 不夠 全面, 多專題的跨層分析無法實現; 並且簡單的把這 些管理業務內容都按如此的模式加入到一個系統中, 又會造成介面複雜系統臃腫, 系統使用人員都是某一 方面的專家, 只會使用其中的一部分功能, 其他部分 對其則是無用的。

綜上所述, 目前的一些城鄉一體化系統在取得了 良好應用效果的同時還暴露出了介面、海量資料、空 間資料的跨區域管理、資料更新、多專題融合等諸多 方面的不足。這些問題迫切的要求一種基於大型 GIS 的城鄉一體的資料中心級的管理工具來管理維護多 級、多層、多源的國土資源資料庫。

\section{2. 城鄉一體化國土資源資料中心管理工具}

\section{1 國土資源資料中心的概念}

國土資源資料中心是一個城鄉一體的資料中心, 它構建在以大型商用資料庫為基礎的大型 GIS 上, 是 包含多種專題資料的國土資源資料倉庫，不僅如此它 還包括了許多按一定標準建立的訪問這些資料的規 範、規則與方法, 通過資料中心可以根據需求對外提 供符合標準的服務而不是傳統的僅僅提供相應的資
料。處在週邊的業務系統模組正是基於這些標準的服 務來構建的, 從而實現了資料與系統之間的相對獨立 性。資料中心的資料庫依據標準來建設並通過相應的 元件提供標準服務, 業務系統不再是傳統的直接訪問 資料庫, 而是通過資料中心提供的符合統一標準的服 務來發出請求獲取服務, 充分的實現系統與資料之間 的異構。

\section{2 城鄉一體化資料中心管理工具}

基於新一代大型 GIS 的城鄉一體資料中心是國土 資源業務管理和資訊服務系統運行的基礎。資料中心 建設包括：運行平臺建設、資料庫建設和相關的維護 工具軟體發展建設、上下級交換體系的建設。

資料中心管理工具是採用先進的插件技術對多專 題資料管理工具模組的有效集成, 能夠跨區域的建設 和整合多級關鍵資料庫, 整合已有多源、多比例尺基 礎資料庫，提高資訊資源的共用水隼。城鄉合一的資 料組織管理和不同專業應用資料的統一組織, 是實現 國土資源資料中心的基礎。系統的資料組織管理模型 基於國土電子政務系統乃至構架“數位城市”, 在此體 系下實現土地利用規劃、建設用地管理、土地的開發 整理、土地市場、礦產資源、定級與估價等業務資料 的結合與管理, 充分考慮系統的擴充性。城鄉一體化 資料中心服務邏輯結構圖如下:

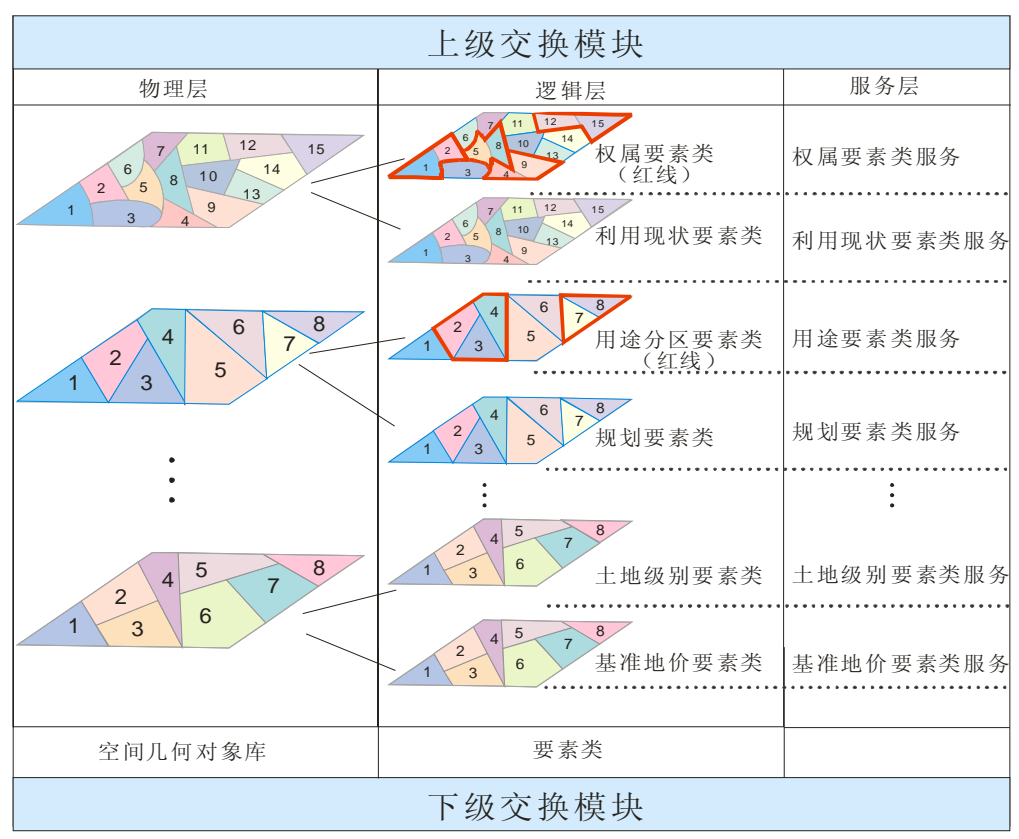

圖 2. 城鄉一體資料中心服務邏輯結構圖 
系統不再有城鄉之分, 只有按行政區域分級結構 的管理業務之分。物理層: 由連續的空間幾何實體 （如：點、線、面實體）構成的空間幾何物件庫無縫 的覆蓋整個轄區; 邏輯層: 專題要素類的實現通過與 空間幾何物件的多種映射關係構成, 土地利用現狀圖 斑與這些物件一一對應的關係, 宗地 ( 權屬單位實體) 由一個或若干個空間幾何物件構成是一對多的關係， 如: 一個行政村可以由若干個物件組成, 同樣一宗地 也可以先由一個或若干個物件組成, 再由空間幾何物 件庫把這些要素類 (專題資料) 融會貫通在一起; 服 務層: 引入物件的概念, 物件不僅包含資料還包括了 操縱資料的介面, 通過邏輯層對資料及與之緊密相關 的操作加以元件化封裝實現對外服務介面, 基於資料 中心的系統開發通過服務進行, 很好的實現了系統與 資料的相對獨立性, 同時良好的支援了應用系統與空 間資料庫之間的異構開發, 資料中心服務按照所操縱 的專題資料的特點可以劃分成很多類 (如: 權屬要素 類、利用現狀要素類、規劃要素類等), 任何一方面 的系統開發可以基於相應的服務類建設, 系統的擴展 可以通過訪問服務類介面的拓寬而發展, 使系統擁有 很好的伸縮性，便於系統的部署和安裝。

“一體化”的真正涵義在於空間資料的一體化組 織。城鄉一體化資料中心是現代國土資源資訊系統的 重要特徵, 是國土資源管理模式的創新, 針對國土資 源管理的核心：權屬管理和土地利用管理, 實現了二 者的有機統一, 進而實現了在此基礎上的規劃、定級 估價、耕地保護等業務專題的高度統一管理, 而不僅 僅是簡單的城鄉地籍資料統一管理。

城鄉一體資料中心管理工具在秉承了前面所述的 兩種模式系統優點的基礎上, 充分利用在大型 GIS 上 的開發成果以及多年在國土資源領域各個業務方面的 已有成果和 IT 業界最新的網路技術, 克服了傳統系統
的缺點, 推出了 MAPGIS 城鄉一體資料中心管理工 具。具體設計結構圖如下圖 3。

\section{3 系統採用的先進技術}

新一代 MAPGIS 的城鄉一體資料中心管理工具利 用了許多業界的新技術新方法, 與傳統的類似系統在 操作簡便性、系統專業性、海量多級多源多專題資料 管理能力方面有著突出的優點, 尤其是如下關鍵技術 發揮了重要作用。

\section{・海量資料管理技術}

基於大型 GIS 技術的國土資源資料中心擁有強 大的海量資料管理能力, 地理地形資料及相應的各 類國土資源專題資料以不規則分塊專題層的方式通 過海量地圖庫進行管理。系統易於針對國土資源資 料管理的特殊性提供給用戶塊與塊間的接邊功能, 易於實現對整體查詢和歸併檢索輸出, 同時保證快 速、高效的性能。

\section{- WEBSERVICES 技術}

資料與系統之間的相對獨立是當今軟體設計的發 展方向, 這種模式既有利於資料的維護利用, 也有利 於資訊系統實現跨平臺超越式的蓬勃發展，基於服務 的系統構建模式正是根據這種狀況應運而生的。利用

元件技術將資料與資料操作進行必要的封裝，以 WEB SERVICES 形式描述這些資料操作訪問的元件 介面, 並且將其形成規範和標準, 應用系統通過 SERVICE 介面實現對資料的訪問。只有規範和標準才 能夠真正最終保障系統獨立性與依賴性的存在, 也才 能很好的支援資料與系統的獨立，從而徹底實現基於 服務的系統異構, WEB SERVICES 技術正是實現這一 目標的技術保障。

- 插件技術

利用已有的程式開發環境來製作插件（程式插

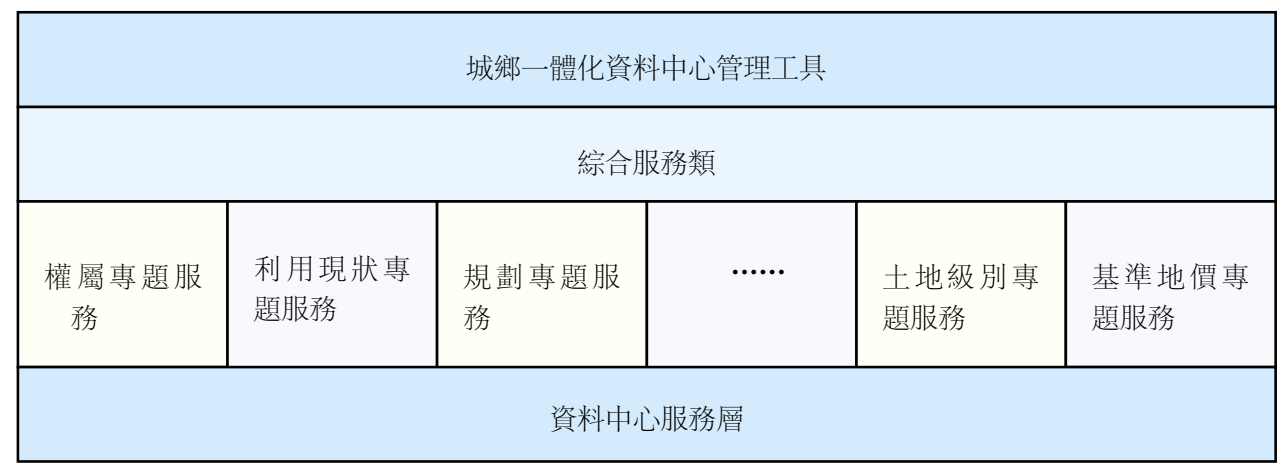

圖 3. MAPGIS 城鄉一體資料中心管理工具設計圖 

件 ），實現真正意義上的軟體元件的“即插即用”。在 二進位級上集成軟體, 減少大量的軟體重新編譯與發 佈麻煩與時間，能夠很好實現軟體模組的分工開發。 將各個專題業務封裝為功能插件, MAPGIS 的城鄉 一體資料中心管理工具系統作為插件的容器, 實現了 功能強大與操作簡約的完美結合。有強大二次開發能 力的用戶還可以利用標準的插件介面開發自己特色的 成果, 所開發成果能自動嵌入容器實現功能擴展, 方 便使用。

\section{・分散式異構空間資料庫技術}

開發基於 GML 的資料轉換服務元件（見下圖 4），實現不同 GIS 系統間資料的集成，實現 GIS 資 料的互操作。由 GML 語言或採用 SOAP 協定引導和 啟動空間資料讀寫與查詢的元件, 從空間資料庫管理 系統中即時讀取空間物件, 並將資料轉換為用 GML 語言定義的公共介面描述規範的資料流程, 其他系統 可以獲取物件資料並進行即時查詢, 可以達到即時線 上資料共用與互操作的目的。

\section{3. 實踐與研究}

南昌市國土資源局通過國土資源大調查已經分別 建立了地籍、土地利用現狀、土地規劃、定級估價四 個方面專題相互獨立的國土資源資料庫。考慮到後續 的日常業務更新，四庫分立的模式會造成資料庫之間 同一空間位置重複更新，邏輯一致性難以保證。與南 昌市局合作應用MAPGIS 城鄉一體化資料中心管理工 具，對專題資料統一設計，加載入與之相對應的管理 插件實現了對多區域（南昌下轄多個縣市）、多專題

（四個方面專題）的統一管理，並且可以很容易的擴 展到同時處理多個專題, 在實際的應用中很好的解決 了城鄉之間、權屬與利用之間統一更新邏輯一致性的 問題, 大大減輕了專題資料的維護工作量, 取得了良 好的社會經濟效益。

統一的資料組織管理模式和資料結構分類體系 下，按土地利用管理、產權產籍管理規劃管理（含礦 產規劃）、定級估價管理等的業務要求，實現了農村 土地和城鎮土地的無縫一體化多專題的國土管理，表

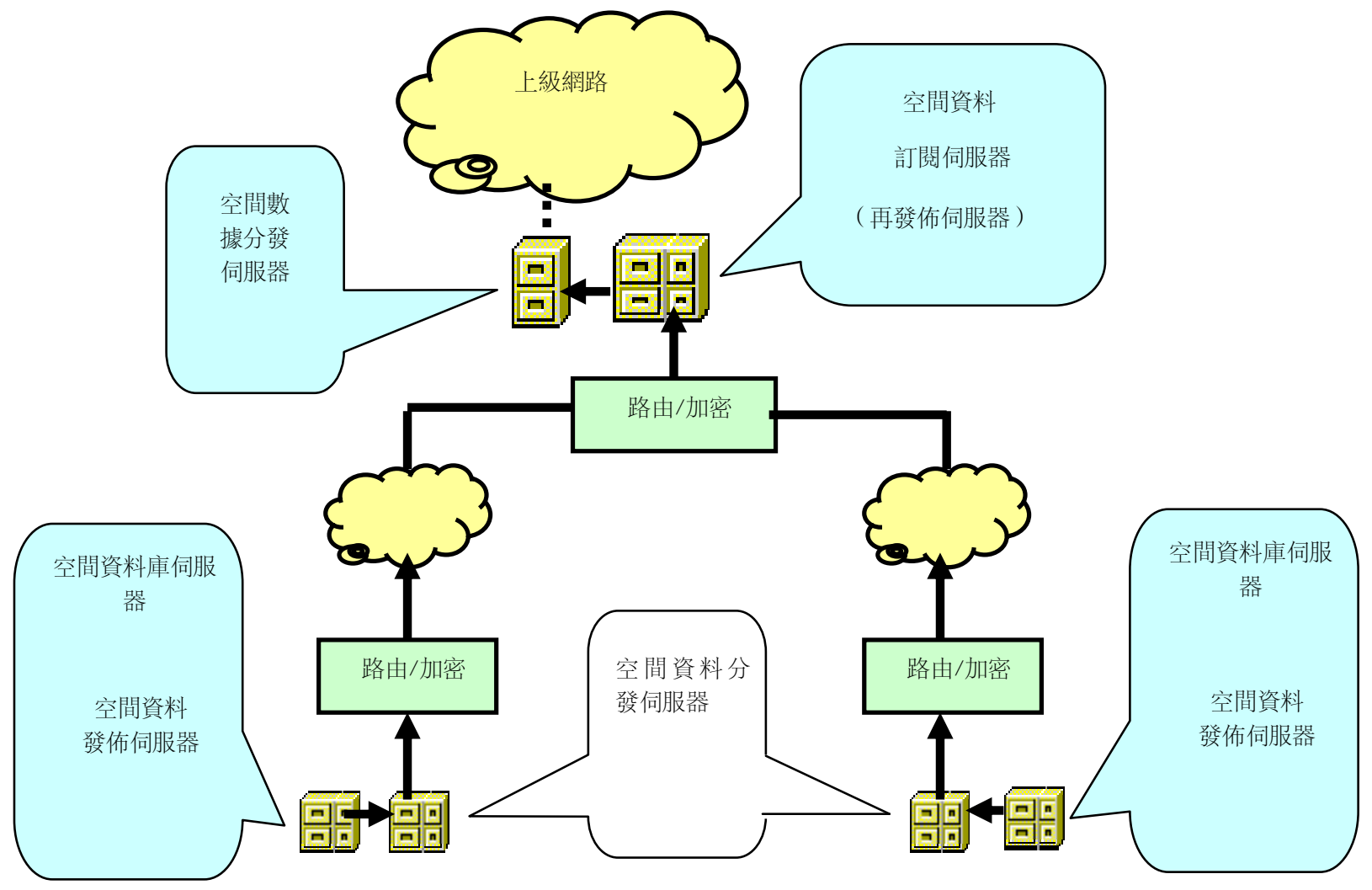

圖 4. MAPGIS 分散式異構空間資料庫結構圖 
現出以下優勢:

·多專題融合統一的資料組織管理模式

物理層邏輯層獨立統一, 合理解決了城鎮地籍調 查街坊、宗地與土地利用現狀調查中的權屬單位、圖 斑的相互銜接及圖斑資訊與宗地資訊的關係, 實現權 屬資訊與土地利用資訊的有機結合和統一管理。

・多級區域資料組織管理模型

系統採用多級區域資料組織管理模型, 實現城鎮 和農村地籍的無縫一體化, 權屬管理和土地利用管理 的一體化, 系統的管理只和省市縣行政區域相關, 與 專題資料多少無關。

・多尺度資料融合

通過統一分帶坐標系海量資料管理以及不規則 接邊帶很好地解決了城鄉不同比例尺之間資料的融 合銜接問題, 使城鎮部分 1: 500 和城郊或農村的 1: 1000、1：2000、1：5000、1：10000 有機地融合在 一起。

\section{- 符合國家相關規範}

按照國土資源部及國家測繪總局相關技術規範設 計, 相容不同的應用要求, 能很好地適用按《全國土 地分類》、過度分類和權屬與土地利用不同分類的應 用要求以及符合國土資源部的各種規程規範。

- 多源資料集成

在城鄉一體化國土資源資料中心系統建設中, 充分利用現代資訊技術, 採用了遙感 GIS、RS、GPS 等技術, 通過多源資料集成, 實現了城鄉一體化向 量、柵格、DEM 等國土資訊資料庫建設及動態更新。 在衛星影像和 DEM 資訊上疊加向量資料, 可直接進 行多專題間資料變更和建設用地審查、土地執法監 察等。

・輔助決策

系統提供的多種跨專題更新查詢分析手段對耕地 保護、制定土地利用總體規劃、退耕還林、老城區拆遷
改造、城市道路改造、土地的存量及利用潛力分析、徵 用土地分析和促進城鄉協調發展等提供了有力的決策 支持。

·系統成果

2004 年 11 月“桂林市國土資源資訊系統”工程獲 科技部、國家測繪局委託中國地理資訊系統協會組織 評選的“地理資訊系統優秀應用工程”金獎。

\section{4. 結論}

國土資源資料中心是存儲著大量國土資源空間資 料和屬性資料的資料倉庫, 它的建立、更新、交換與 服務直接關係到政務系統的良好運行, 必需有合適的 與之相匹配的工具系統來維護它的各種一致性才能保 障其正常有序的運轉。城鄉一體化國土資源資料中心 管理工具的建設正是基於此提出的, 它是國土資源資 料中心的核心模組, 包含了為多級、多源、多尺度的 海量國土資源資料維護而量身定做的多種專用工具, 採用了多層設計插件技術, 實現各個專題之間物理與 邏輯設計的獨立統一, 邏輯層面解決了國土資源統一 管理的問題, 物理實現層面也簡化了開發難度, 大大 簡化了資料中心的維護操作過程, 推廣到實際應用中 後獲得了良好的評價。

\section{參考文獻 (References)}

[1] 武漢大學電子政務研究中心. 城市電子政務軟體平臺 技術與系統設計. 武漢大學出版社, 2004.

[2] 國土資源部資訊化工作室. 關於國土資源電子政務指 導意見. 國土資源資訊化, 2004 年第 3 期.

[3] 貴州省國土資源廳. 明確目標抓住關鍵努力推進國土 資源電子政務建設. 國土資源通訊, 2004 年第 10 期.

[4] 在國土資源電子政務建設工作會議上的講話. 國土資 源通訊, 2004 年第 7 期.

[5] 貴州省國土資源資訊中心. 省級國土資源電子政務建 設特點探討. 國土資源資訊化, 2004 年第 1 期.

[6] 謝元禮, 胡斌. 淺談 GIS 的發展歷程與趨勢. 地理資訊 系統論壇, 2005,3. 